\title{
Sustainable cement mortars
}

\author{
Teresa Rucińska ${ }^{1, *}$ \\ ${ }^{1}$ Department of Building Physics and Building Materials, Faculty of Civil Engineering and \\ Architecture, West Pomeranian University of Technology Szczecin, al. Piastów 50, 70-310 Szczecin, \\ Poland
}

\begin{abstract}
The results described here on the basic technical parameters of cement mortars made from fine-grained concrete recyclate, ceramic recyclate, and slag, obtained from the incineration of municipal sewage sludge, demonstrate their usefulness in the production of building materials. Changes were introduced to the composition of cement mortars involving the replacement of natural aggregate with recyclate of the same fraction in the following volumes: $10 \%, 20 \%$ and $30 \%$. The physicomechanical characteristics constitute the basis for further research which will help determine their practical applications.
\end{abstract}

\section{Introduction}

The pace of civilisation's development, apart from offering a number of positive effects, contributes to the depletion of natural resources, including fossil fuels. In view of this, recent years have seen significant progress in ecological engineering dictated by the EU Directives stemming from the principles of sustainable development. The obligation to meet these stringent environmental standards enforced by the EU requires the adoption of measures towards the search and development of innovative solutions. One of the priorities in this area is the use of waste materials in building materials technology. Such requirements are set out in the Regulation of the European Parliament and of the EU Council No. 305/2011 of 9 March 2011 [1]. It is assumed that in 2020, Poland will reach the recycling ceiling of up to $50 \%$, and $65 \%$ in 2030 [2].

The possibility to use waste materials for the production of building materials has been emphasised by a number of researchers [3-10]. Among others, this involves the use of glass cullet, concrete and ceramic waste, fly ash, sludge [11], etc.

To address this research trend, simultaneously taking into account the environmental aspect and the growing amount of construction waste, the author carried out experimental studies on cement mortars containing fine-grained recyclates obtained through the grinding of concrete and ceramic debris and the incineration of sewage sludge.

\footnotetext{
* Corresponding author: Teresa.Rucinska@zut.edu.pl
} 


\section{Materials and methods}

\subsection{Materials}

The cement mortars were based on the Portland CEM I 42R cement from the cement plant Górażdże $\left(\rho=3.11 \mathrm{~g} / \mathrm{cm}^{3}\right)$, natural sand (Fig. 1) taken from the local mineral mine in Bielinek (Poland) and tap water in accordance with PN-EN 197-1. The following recyclates were used: concrete (Fig. 2), ceramic (Fig. 3) and incinerated sludge - slag (Fig. 4), which were fine ground in a ball mill to receive the appropriate fraction. The natural sand grain size curve used in the determination of the share of individual fractions in the aggregates obtained from concrete and ceramic waste and incinerated sewage sludge is presented in Fig. 5.

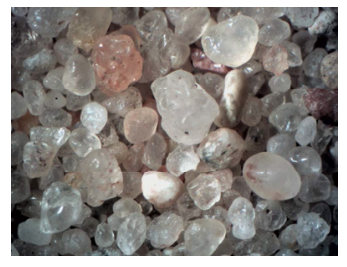

Fig. 1. Grains of natural sand.

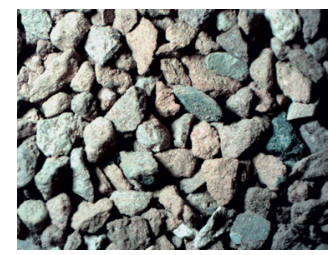

Fig. 3. Grains of ground ceramic waste.

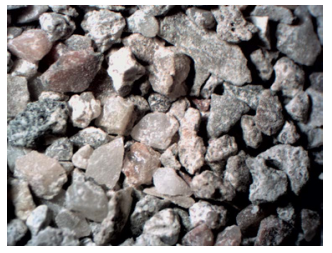

Fig. 2. Grains of ground concrete waste.

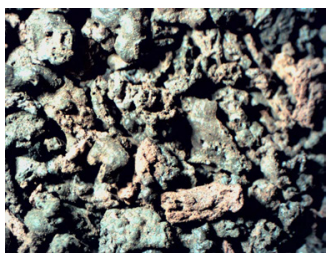

Fig. 4. Grains of incinerated sewage sludge.

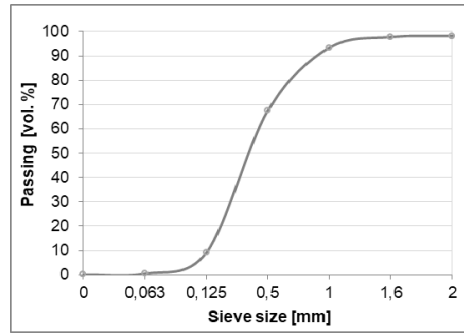

Fig. 5. Natural sand grain size curve.

The evaluation of the shape of recyclate grains with respect to natural sand shows that they are angular with rough surfaces (Fig. 6a-8b). It is also worth noting that grains obtained by grinding concrete waste are, in their pure form, mostly granular aggregate produced of coarse fraction grains (Fig. 2) which is a component of concrete.

Based on the analysis of the elemental composition (Fig. 6b, 7b, 8b), concrete rubble does not contain or contains only a small percent of harmful chemical elements that could threaten human health or negatively affect the environment. This gives a feeling of safety when using these wastes, particularly in masonry mortars as well as ceiling and plaster coatings. 
a)

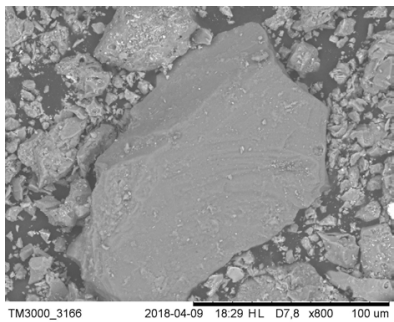

b)

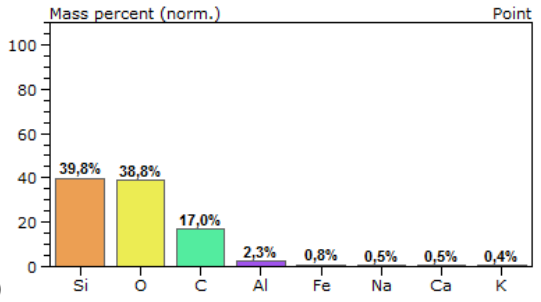

Fig. 6. a) Grains of ceramic recyclate; b) elemental composition of raw ceramic material.

a)

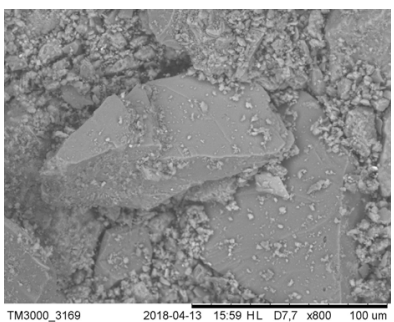

b)

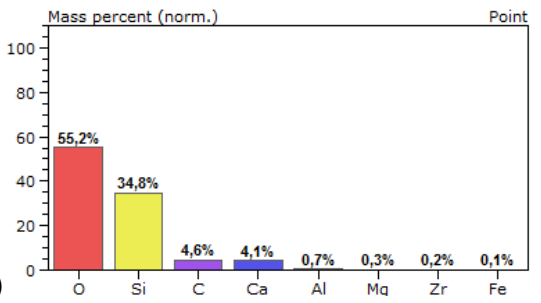

Fig. 7. a) Grains of concrete recyclate; b) elemental composition of raw concrete material.

a)

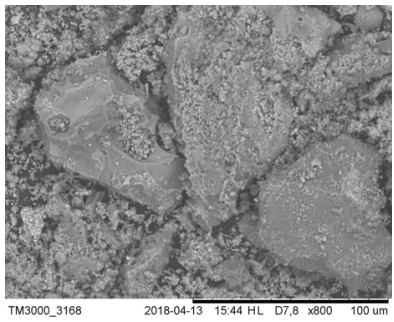

b)

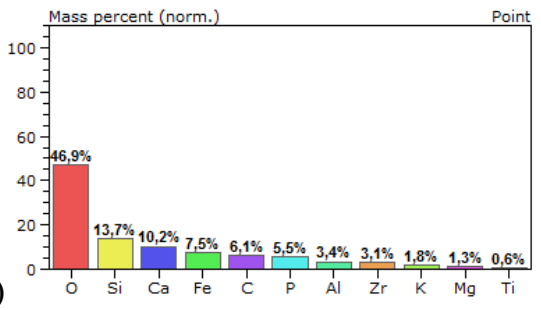

Fig. 8. a) Grains of slag; b) elemental composition of incinerated sewage sludge.

The preparation of the composition of specific mortars required the determination of the density of recyclates (Table 1.).

Table 1. Overview of densities of natural and recycled aggregates.

\begin{tabular}{|c|c|}
\hline Type of fine-grained aggregate & $\begin{array}{c}\text { Density } \\
{\left[\mathbf{g} / \mathbf{c m}^{\mathbf{3}}\right]}\end{array}$ \\
\hline Natural sand & 2.65 \\
\hline Obtained from concrete waste & 2.59 \\
\hline Obtained from ceramic waste & 2.68 \\
\hline Incinerated sewage sludge & 2.86 \\
\hline
\end{tabular}

What is also important is that the recycled aggregate clearly demonstrated the absorption of water which points to the porous structure of grains as well as a higher water demand due to the greater specific surface area (sharp-edged grains with coarse surface) in relation to natural sand (oval grains with majority consisting of quartz). This results in the need of adding to the mortar mixtures an extra dose of water which is not involved in the hydration process. During the maturation, this dose of water contributes to increasing the level of self-care in the aggregate-cement matrix contact zone, which in turn leads to 
improving the tensile strength of the composite. However, this has negative consequences as well. Unused in the hydration process, the evaporating water is the source of micropores that weaken the composite structure. However, it must be borne in mind that, in terms of practical applications, there exists a need for mortars of varied technical parameters. The use of recyclates of porous structure allows obtaining mortars of lower density while maintaining their beneficial insulation qualities.

\subsection{Composition and preparation of mortars}

The studied cement mortars are characterised by a fixed cement-aggregate-water ratio, which is 1:3:0.5. Four types of mortars were prepared with each group substituting (successively) $10 \%, 20 \%$ and $30 \%$ of natural aggregate with specific recyclate type by volume. Eventually, 10 mortar mixtures were examined and labelled according to the following pattern:

- reference mortar - R, 100\% natural fine-grained aggregate (sand),

- mortar with ceramic recyclate - RC (RC10, RC20 and RC30),

- mortar with concrete recyclate - RB (RB10, RB20 and RB30),

- mortar with sewage sludge (slag) - RO (RO10, RO20 and RO30).

Batch water in these mortars was supplemented with absorbed water during mixing of the components by the recycled aggregate. The amount of additional water was added experimentally so as to obtain the appropriate consistency of the mixture in relation to the reference mortar determined by means of a vortex mixer (PN-EN 1015-3). After forming, the samples were kept in a tub above water at a temperature of $20^{\circ} \mathrm{C} \pm 2{ }^{\circ} \mathrm{C}$ and at relative humidity of $\geq 95 \%$. Then, they were unformed and stabilised in the same conditions until the successive studies were performed.

Table 2 shows the composition of individual mortars.

Table 2. Mortar composition.

\begin{tabular}{|c|c|c|c|c|c|c|c|c|c|c|}
\hline \multirow{2}{*}{$\begin{array}{c}\text { Components } \\
\text { content } \\
{\left[\mathrm{kg} / \mathrm{m}^{3}\right]}\end{array}$} & \multicolumn{10}{|c|}{ Sample designation } \\
\hline & $\mathbf{R}$ & RC10 & RC20 & RC30 & RB10 & RB20 & RB30 & RO10 & RO20 & RO30 \\
\hline Cement & 512 & 512 & 512 & 512 & 512 & 512 & 512 & 512 & 512 & 512 \\
\hline Water & 256 & 256 & 256 & 256 & 256 & 256 & 256 & 256 & 256 & 256 \\
\hline River sand & 1,536 & 1,380 & 1,223 & 1,066 & 1,380 & 1,223 & 1,066 & 1,380 & 1,223 & 1,066 \\
\hline Ceramic waste & - & 156.5 & 313 & 470 & - & - & - & - & - & - \\
\hline Concrete waste & - & - & - & - & 152.5 & 304.9 & 457.5 & - & - & - \\
\hline Waste slag & - & - & - & - & - & - & - & 165.9 & 331.8 & 497.6 \\
\hline Additional water & - & 27.23 & 51.69 & 81.03 & 17.43 & 19.91 & 28.83 & 58.06 & 127.5 & 176.7 \\
\hline
\end{tabular}

\subsection{Study methods}

Consistency of fresh mortar was determined by means of the vortex mixer according to PN-EN 1015-3. The flexural strength and the compressive strength were determined in accordance with PN-EN 197-1 after 7 and 28 days of maturation. For the purpose of the study, each mortar mixture was formed into a small beam of $40 \times 40 \times 160 \mathrm{~mm}$. The examination of mortar absorptivity was carried out by means of the water absorption method, which consisted in immersing the beam-shaped samples of $40 \times 40 \times 160 \mathrm{~mm}$ in water in accordance with PN-B-04500:1985. The thermal conductivity coefficient was 
determined by means of the non-stationary method using the ISOMET 2104 camera equipped with contact probes. Rectangular $100 \times 100 \times 50 \mathrm{~mm}$ samples were prepared for test purposes.

\section{Results and discussion}

The point of reference for the measured values of technical parameters of recycled aggregate cement mortars was the reference cement mortar, with $100 \%$ content of natural sand as fine-grained aggregate. This allowed assessing the impact of the introduced recyclate volume content in relation to the volume of fine-grained aggregate on the properties of individual mortars.

\subsection{Consistency and density}

The reference mortar at $\mathrm{w} / \mathrm{c}=0,5$ was characterised by consistency of a diameter of $140 \mathrm{~mm}$. In order for the recyclate mortars to achieve a similar mixture distribution, the experimentally regulated addition of water was necessary. The amount added resulted in the growth of the w/c coefficient depending on the porosity of the rubble and its specific surface area - Table 2 . It can be clearly seen that the minimum amount of water was absorbed by the concrete aggregate, while the maximum amount was taken in by the sewage sludge (slag). As it was already mentioned, the majority of aggregate grains produced by grinding concrete waste is the fine-grained form of the natural coarse aggregate (Fig. 2). The slag, on the other hand, apart from having a rough surface, is characterised by high porosity (Fig. 9), which confirms its greater level of water absorption.

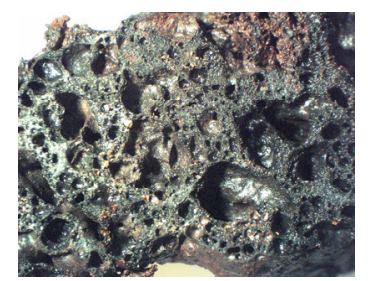

Fig. 9. Image of microstructure of slag enlarged 10x.

The confirmation of the porous structure of grains produced by means of grinding concrete and ceramic construction waste and incinerating sewage sludge is manifested by the values of volume density of different mortars - Table 3 .

Table 3. Density of mortars.

\begin{tabular}{|c|c|c|c|c|c|c|c|c|c|c|}
\hline \multirow{2}{*}{$\begin{array}{c}\text { Density } \\
{\left[\mathbf{k g} / \mathbf{m}^{\mathbf{3}}\right]}\end{array}$} & $\mathbf{8}$ & $\mathbf{R C 1 0}$ & $\mathbf{R C 2 0}$ & $\mathbf{R C 3 0}$ & $\mathbf{R B 1 0}$ & $\mathbf{R B 2 0}$ & $\mathbf{R B 3 0}$ & $\mathbf{R O 1 0}$ & $\mathbf{R O 2 0}$ & $\mathbf{R O 3 0}$ \\
\cline { 2 - 11 } & $\mathbf{R}$ & 2,090 & 2,050 & 2,030 & 2,080 & 2,060 & 2,040 & 2,060 & 2,000 & 1,950 \\
\hline $\begin{array}{c}\text { Volume density } \\
\text { of mixture }\end{array}$ & 2,120 & 2,050 & 1,90 & 1,960 & 1,970 & 1,860 & 1,780 \\
\hline $\begin{array}{c}\text { Volume density } \\
\text { in dry state }\end{array}$ & 2,070 & 2,020 & 1,940 & 1,900 & 2,020 & 1,990 & 1,90 & 140 & 170 \\
\hline Water loss, kg & 50 & 70 & 90 & 130 & 60 & 70 & 80 & 90 & 140 \\
\hline
\end{tabular}


As follows from the values of volume density, the major part of water added to the mixture evaporated during the sample drying process. This is confirmed by the fact that this water was not involved in the hydration of cement and that the recyclate grains demonstrate varied porosity levels.

\subsection{Flexural and compression strength}

The flexural and compression strength were assessed after 7 and 28 days of maturation of mortars stabilized at $20^{\circ} \mathrm{C}$ and $\mathrm{RH} \geq 95 \%$. The obtained average values are presented in Table 4.

Table 4. Flexural and compression strength of mortars after 7 and 28 days of maturation.

\begin{tabular}{|c|c|c|c|c|}
\hline \multirow{2}{*}{$\begin{array}{c}\text { Sample } \\
\text { designation }\end{array}$} & \multicolumn{2}{|c|}{$\begin{array}{c}\text { Flexural strength } \\
\text { [MPa] }\end{array}$} & \multicolumn{2}{c|}{$\begin{array}{c}\text { Compressive strength } \\
\text { [MPa] }\end{array}$} \\
\cline { 2 - 5 } & $\begin{array}{c}\text { After 7 days of } \\
\text { maturation }\end{array}$ & $\begin{array}{c}\text { After 28 days of } \\
\text { maturation }\end{array}$ & $\begin{array}{c}\text { After 7 days of } \\
\text { maturation }\end{array}$ & $\begin{array}{c}\text { After 28 days of } \\
\text { maturation }\end{array}$ \\
\hline R & 4.97 & 6.51 & 35.05 & 47.21 \\
\hline RC10 & 5.25 & 6.60 & 32.50 & 45.50 \\
\hline RC20 & 5.15 & 6.15 & 28.80 & 41.25 \\
\hline RC30 & 4.65 & 5.90 & 25.35 & 34.35 \\
\hline RB10 & 5.09 & 6.58 & 34.67 & 44.07 \\
\hline RB20 & 5.09 & 6.31 & 33.43 & 43.00 \\
\hline RB30 & 4.92 & 6.21 & 30.72 & 40.83 \\
\hline RO10 & 5.66 & 5.90 & 35.10 & 41.95 \\
\hline RO20 & 4.42 & 4.60 & 26.83 & 33.87 \\
\hline RO30 & 4.33 & 4.32 & 20.87 & 28.74 \\
\hline
\end{tabular}

Presented in table 4, the values of flexural and compression strength indicate a close relationship with the amount of recyclate dosed as well as its type. Compared to the reference mortar, the concrete recyclate mortar achieved the highest values. Slightly lower values were obtained by the ceramic recyclate mortar. The sewage sludge mortar, along with the increasing volume content of the aggregate, is characterised by the greatest reduction in strength, as is particularly noticeable in the case of the RO30 mortar. However, it should be noted that in accordance with PN-EN 998-2, these mortar mixtures can be classified as Md which is characterised by compressive strength values higher than $25 \mathrm{MPa}$.

If we assume that the flexural strength of the tested mortar mixtures is close to their tensile strength, then their comparison with compression strength should allow the estimation of the brittleness of these composites; namely, the all mortar mixtures are characterised by a beneficial ratio of these strengths, which ranges between 0.14 and 0.15 , with the ceramic recyclate mortar RC30 reaching 0.17 . Bearing in mind the limit value of the brittleness coefficient of 0.125 , it can be claimed that the rough surface of the open-pore aggregate grains, in combination with its high water absorption rate enhances cooperation in the cement matrix-aggregate contact zone. Water absorbed by the aggregate grains evaporates over time which results in the phenomenon of contact area self-care, which in turn contributes to improved tensile strength.

\subsection{Absorptivity and moisture}

While being different in respect of individual recycled aggregates, the high porosity values of recycled aggregate mortars show higher absorptivity and the capacity of sorptive absorption of water in relation to mortars consisting only of natural sand - Table 5. 
Table 5. Absorptivity and moisture of the examined mortars.

\begin{tabular}{|c|c|c|}
\hline $\begin{array}{c}\text { Sample } \\
\text { designation }\end{array}$ & $\begin{array}{c}\text { Absorptivity } \\
{[\mathbf{\%}]}\end{array}$ & $\begin{array}{c}\text { Moisture } \\
{[\mathbf{\%}]}\end{array}$ \\
\hline $\mathrm{R}$ & 7.26 & 6.44 \\
\hline $\mathrm{RC} 10$ & 7.46 & 6.82 \\
\hline $\mathrm{RC} 20$ & 8.49 & 7.82 \\
\hline $\mathrm{RC} 30$ & 9.90 & 9.12 \\
\hline $\mathrm{RB} 10$ & 7.28 & 6.70 \\
\hline $\mathrm{RB} 20$ & 7.35 & 6.76 \\
\hline $\mathrm{RB} 30$ & 8.53 & 7.58 \\
\hline $\mathrm{RO} 10$ & 9.45 & 8.72 \\
\hline $\mathrm{RO} 20$ & 12.44 & 11.27 \\
\hline $\mathrm{RO} 30$ & 14.46 & 13.56 \\
\hline
\end{tabular}

Mortars with sewage sludge content with porosity higher than the concrete and ceramic aggregate is characterised by high absorptivity. It must be remembered that the effect of water on the porous building materials is negative and is further intensified along with the increase of pore size in their structure. This means that the analysed mortars will have limited application unless it is demonstrated that protecting them from the harmful effect of water is cost-effective.

The moisture content of the analysed cement mortars presented in Table 4 . is the result of their stabilisation for 28 days at $20^{\circ} \mathrm{C}$ and at $\mathrm{RH} \geq 95 \%$. A comparison of moisture content with absorptivity demonstrates that the analysed mortars are a good adsorbent [12] and thus show a high capacity to absorb water from the environment.

\subsection{Thermal conductivity}

The decreasing volume density of the mortars along with the increasing recyclate content, as well as recyclate type have a beneficial effect on the thermal conductivity in terms of thermal insulation - Table 6 .

Table 6. Thermal conductivity.

\begin{tabular}{|c|c|c|c|}
\hline \multirow{2}{*}{$\begin{array}{c}\text { Sample } \\
\text { designation }\end{array}$} & \multicolumn{2}{|c|}{ Thermal conductivity [W/(m·K)] } & \multirow{2}{*}{ Ds /Ws ratio } \\
\cline { 2 - 3 } & in wet state & in dry state & \\
\hline $\mathrm{R}$ & 2.42 & 1.79 & 0.74 \\
\hline $\mathrm{RC} 10$ & 2.11 & 1.54 & 0.73 \\
\hline $\mathrm{RC} 20$ & 1.96 & 1.35 & 0.69 \\
\hline $\mathrm{RC} 30$ & 1.84 & 1.29 & 0.70 \\
\hline $\mathrm{RB} 10$ & 2.27 & 1.64 & 0.72 \\
\hline $\mathrm{RB} 20$ & 2.04 & 1.50 & 0.74 \\
\hline $\mathrm{RB} 30$ & 2.01 & 1.44 & 0.72 \\
\hline $\mathrm{RO} 10$ & 2.11 & 1.57 & 0.74 \\
\hline $\mathrm{RO} 20$ & 1.85 & 1.23 & 0.66 \\
\hline $\mathrm{RO} 30$ & 1.50 & 0.93 & 0.62 \\
\hline
\end{tabular}

In each mortar group, a clear beneficial effect can be observed on the values of the thermal conductivity along with the increasing content of recyclate in the mortar. This is best observed in the case of the sewage sludge mortar which demonstrates the highest porosity compared to 
other aggregate types. The thermal conductivity in a dry state at $30 \%$ of volume content of sewage sludge in the mortar in comparison with the reference mortar is decreased by up to $48 \%$. In the case of ceramic recyclate, this number is $28 \%$, and in the case of concrete recyclate $-20 \%$. Therefore, in each case there is an decrease in the thermal conductivity, which is very important in view of the popularity of energy-efficient construction $[13,14]$.

\section{Conclusions}

The findings from this study on cement mortars with fine-grained recyclate content provide a basis for their classification at least as masonry mortars according to EN 998-2.

The volume density of the mortars decreased along with an increase in the recyclate content in the mixture. Moreover, this parameter was also influenced by the type of waste used.

Although a noticeable decrease in compressive strength was observed in the $30 \%$ recyclate content mortar compared with $100 \%$ natural aggregate volume content mortar, the recyclate mortar mixtures can be classified in terms of their compressive strength as $\mathrm{Md}$ of guaranteed compressive strength higher than $25 \mathrm{MPa}$.

The porous structure of the recycled aggregate grains, together with the open nature of the pores, is beneficial to the cement matrix-aggregate join layer.

The thermal conductivity of the mortars is significantly lower compared to the $100 \%$ natural sand reference mortar, which has a positive effect on the reduction of thermal bridges in the wall-mortar connection area.

In summary, fine-grained recycled aggregates in the form of concrete and ceramic waste as well as sewage sludge can successfully be used in the production of building materials.

\section{References}

1. Regulation of the European Parliament and of the EU Council No. 305/2011 of 9 March 2011 (2011)

2. E. Kołaczek, (Nowy system gospodarki odpadami komunalnymi, Ministerstwo Środowiska Warszawa, 2012)

3. M. Bołtryk, K. Kalinowska-Wichrowska, Materiały Budowlane, 8, 54-55 (2017)

4. Ł. Gołek, E. Kapeluszna, Świat Szkła 5, 42-44 (2013)

5. J. Jura, J. Halbiniak, M. Ulewicz, Materiały Ceramiczne, T.67 (4), 438-442 (2015)

6. Kuśnierz A., (Recykling szkła, Prace Instytutu Ceramiki i Materiałów Budowlanych, R. 3 (6), 438-442 (2010)

7. T. Rucińska, K. Łącka, Materiały Budowlane 10, 22-24 (2016)

8. P. Sikora, A. Augustyniak, K. Cendrowski, E. Horszczaruk, T. Rucinska, P. Nawrotek, E. Mijowska, Materials 9(8), 701 (2016)

9. P. Sikora, K. Cendrowski, A. Markowska-Szczupak, E. Horszczaruk, E. Mijowska, Constr. and Build. Mat. 150, 738-746 (2017)

10. P. Sikora, E. Horszczaruk, T. Rucińska, A. Straszyńska, Materiały Budowlane 5, 116-118 (2015)

11. A. Głowacka, T. Rucińska, J. Kiper, E3S Web Conf., 22 (2017)

12. A. Siwińska, J. Strzałkowski, Energy Procedia 78, 1437-1442 (2015)

13. J. Strzałkowski, H. Garbalińska, Adv. in Cem. Res., 28, 567-575 (2016)

14. J. Strzałkowski, H. Garbalińska, Journal IOP, Mat. Sci. and Eng., 245, 1-10 (2017) 